\title{
Color Excipient
}

National Cancer Institute

\section{Source}

National Cancer Institute. Color Excipient. NCI Thesaurus. Code C42656.

Therapeutically inactive dye or coloring agent that is a component of pharmaceutical product. There are the more than 100 excipient colors approved by the FDA for pharmaceutical use. 